Western University

Scholarship@Western

Biology Publications

Biology Department

Spring 2019

Overwintering Red Velvet Mites Are Freeze Tolerant

Susan E. Anthony

Western University, santho2@uwo.ca

Brent J. Sinclair

Western University, bsincla7@uwo.ca

Follow this and additional works at: https://ir.lib.uwo.ca/biologypub

Part of the Biology Commons

Citation of this paper:

Anthony, Susan E. and Sinclair, Brent J., "Overwintering Red Velvet Mites Are Freeze Tolerant" (2019).

Biology Publications. 104.

https://ir.lib.uwo.ca/biologypub/104 


\section{Overwintering red velvet mites are freeze tolerant}

2 Freeze-tolerant mite

$4 \quad$ Susan E. Anthony ${ }^{1 *} \&$ Brent J. Sinclair ${ }^{1}$

5

$6 \quad{ }^{1}$ Department of Biology, University of Western Ontario, London, ON, Canada

8 *Correspondence: Susan Anthony, Dept. Biology, University of Western Ontario,

9 London, ON, N6A 5B7, Canada

10 santho2@uwo.ca; Tel. +1-519-661-2111x89158; Fax +1-519-661-3935

\section{What is already known:}

13 Freeze-tolerance, the ability to survive freezing, has evolved in many arthropod species

14 and in the arachnids, only in scorpions. All the microarthropods (mites and collembolans)

15 that have been studied have been freeze avoidant, and have been assumed to be

16 constrained to this strategy because of their small size. This has led researchers to

17 conclude that freeze avoidance is a basal trait.

\section{What this study adds:}

19 We find a mite that is freeze tolerant - the first known instance of this strategy in any mite or

20 microarthropod. This means that microarthropods are not, in fact, constrained to freeze

21 avoidance, and that our thought processes about the evolution of freeze tolerance might need

22 revision. 


\section{Abstract}

24 Although many arthropods are freeze-tolerant (able to withstand internal ice), small-bodied

25 terrestrial arthropods such as mites are thought to be constrained to freeze avoidance. We field-

26 collected active adult red velvet mites, Allothrombium sp. (Trombidiidae), in winter in

27 Southwestern Ontario, Canada, where temperatures drop below $-20^{\circ} \mathrm{C}$. These mites froze

28 between -3.6 and $-9.2^{\circ} \mathrm{C}$ and survived internal ice formation. All late-winter mites survived being

29 frozen for $24 \mathrm{~h}$ at $-9^{\circ} \mathrm{C}$, and $50 \%$ survived one week. The $\mathrm{LLT}_{50}$ (the low temperature that kills

$3050 \%$ of mites) was c. $-20^{\circ} \mathrm{C}$ in midwinter. Hemolymph osmolality and glycerol concentration

31 increased in midwinter, accompanied by decreased water content. Thus, this species is freeze

32 tolerant, demonstrating that there is neither phylogenetic nor size constraint to evolving this cold

33 tolerance strategy.

\section{Keywords}

37 Freeze tolerance, Acari, seasonality, cold hardiness, overwintering, cryoprotectant 


\section{Introduction}

Winter temperatures drop below $0^{\circ} \mathrm{C}$ in terrestrial temperate, polar, and alpine ecosystems. Arthropods in these habitats generally adopt one of two cold tolerance strategies:

41 freeze avoidance, preventing ice formation by depressing the temperature at which they freeze

42 (the supercooling point, SCP), or freeze tolerance, withstanding internal ice formation (Lee

43 2010). Freeze-tolerant insects accumulate low molecular weight cryoprotectants, such as glycerol

44 or proline (Lee 1991). They have high SCPs that likely facilitate control of the site or rate of ice

45 formation (Toxopeus and Sinclair in press). Finally, freeze tolerant insects sometimes produce

46 ice-binding proteins that initiate freezing at high temperatures (ice nucleating proteins) or control

47 the growth and distribution of ice crystals (thermal hysteresis and recrystallisation-inhibiting

48 proteins; Zachariassen and Kristiansen 2000).

Freeze tolerance appears to be a derived trait that has evolved multiple times in

50 arthropods (Sinclair et al. 2003; Toxopeus and Sinclair in press), including many Insecta,

51 Chilopoda, Crustacea, and in two Arachnids (both scorpions; Crawford and Riddle 1975;

52 Whitmore et al. 1985). Small arthropods contain a small volume of water and therefore supercool

53 easily (Sinclair et al. 2003). This propensity to supercool probably predisposes them towards

54 freeze avoidance (Cannon and Block 1988). In particular, there has been extensive work on the

55 cold tolerance of mites (Acari) and springtails (Collembola; collectively 'microarthropods') in

56 the Antarctic and Arctic (as well as non-polar regions; Cannon and Block 1988; Sjursen and

57 Sømme 2000), and thus far all have been freeze-avoidant or chill-susceptible. This is despite

58 many of those species having soft permeable bodies and occupying the ice-rich microhabitats

59 likely to promote inoculation by external ice and therefore freeze tolerance (Sinclair et al. 2003).

60 Thus, the general conclusion is that - whether due to their small size or phylogenetic constraints 
61 - microarthropods do not evolve freeze tolerance (Cannon and Block 1988; Sinclair et al. 2003;

62 Toxopeus and Sinclair in press).

63

64 Here we report that overwintering red velvet mites are freeze tolerant, extending the

65 taxonomic breadth of incidence of this strategy and upending the expectation that all

66 microarthropods are freeze avoidant.

67

68 Methods

69 We hand-collected a total of 340 adult red velvet mites [Allothrombium sp.

70 (Trombidiidae), voucher CNC871154, Canadian National Collection], mean \pm SEM fresh mass

$714.3 \pm 0.2 \mathrm{mg}$, from the soil surface and leaves of Cirsium arvense at the Environmental Sciences

72 Western farm in Ilderton, Ontario $\left(43.1^{\circ} \mathrm{N}, 81.3^{\circ} \mathrm{W}\right)$ between March 2016 and May 2017. To

73 access mites under snow in winter, we collected c. 100 individuals in November 2016 and buried

74 them in 'field cages' $-600 \mathrm{~mL}$ plastic containers containing $2 \mathrm{~cm}$ of soil and C. arvense leaves,

75 such that the surface of the soil in the containers was level with the surrounding soil. After

76 collecting them from the field or removing them from the field cages (the mites always remained

77 on the surface of the soil), we housed mites in $600 \mathrm{~mL}$ containers at $4{ }^{\circ} \mathrm{C}$ (winter - January,

78 February, March) or room temperature (spring - April, May and autumn - November) for up to

79 five days. We were unable to find mites between May and September, likely because juvenile

80 trombindinid red velvet mites are ectoparasitic (Zhang 1998). We determined the SCP, cold

81 tolerance strategy, and low temperature at which $50 \%$ of individuals are killed (LLT T0 $_{50}$ using

82 methods outlined elsewhere (Sinclair et al. 2015). 
We measured SCP in March, April, September, October, and November 2016, and

84 January, February, March, and May 2017. We placed mites individually in $1.7 \mathrm{~mL}$

85 microcentrifuge tubes in contact with a 36-AWG type-T thermocouple and recorded temperature

86 at $2 \mathrm{~Hz}$ via a TC-08 interface and PicoLog software (Pico Technology, Cambridge, UK). We

87 placed tubes in an aluminium block cooled by fluid circulated from a Proline RP855 bath

88 (Lauda, Würzburg, Germany; before July 2016) or by a custom-built Peltier-effect device. We

89 cooled mites from $4^{\circ} \mathrm{C}$ (winter) or $20^{\circ} \mathrm{C}$ (spring and autumn) to $0^{\circ} \mathrm{C}$ at $1.0^{\circ} \mathrm{C} \cdot \mathrm{min}^{-1}$, and

$90 \quad 0.5^{\circ} \mathrm{C} \cdot \mathrm{min}^{-1}\left(\right.$ or $0.25^{\circ} \mathrm{C} \cdot \mathrm{min}^{-1}$ before July 2016) thereafter.

91

92

To determine cold tolerance strategy in March, September, October, and November 2016,

93 and January 2017, we cooled groups of mites until half the individuals had frozen (i.e. produced

94 exotherms), then removed all of them to $4^{\circ} \mathrm{C}$ (winter) or $\sim 20^{\circ} \mathrm{C}$ (spring and autumn). After $24 \mathrm{~h}$,

95 mites that were upright and moving were recorded as alive.

96

We estimated LLT 50 in March and November 2016, and January 2017 in groups of four

98 mites exposed for $1 \mathrm{~h}$ to a range of temperatures below the SCP. We began cooling at $21^{\circ} \mathrm{C}$ (for

99 March measurements), $15^{\circ} \mathrm{C}$ (November), or $4{ }^{\circ} \mathrm{C}$ (January; we based these temperatures on

100 approximate maximum air temperatures for each month), and cooled and rewarmed at $0.25^{\circ} \mathrm{C}$

$101 \min ^{-1}$ (March measurements), or to $0^{\circ} \mathrm{C}$ at $1^{\circ} \mathrm{C} \cdot \mathrm{min}^{-1}$, and $0.5^{\circ} \mathrm{C} \cdot \mathrm{min}^{-1}$ thereafter, and rewarmed

102 at $0.5^{\circ} \mathrm{C} \cdot \mathrm{min}^{-1}$. We assessed survival after $24 \mathrm{~h}$ at $20^{\circ} \mathrm{C}$ (March, November) or $4^{\circ} \mathrm{C}$ (January).

103

104 We examined survival after prolonged freezing at temperatures below the SCP (but that 105 yielded 100\% survival of brief exposures) in April 2016 and March 2017. We cooled groups of 
$1067-10$ mites from $21^{\circ} \mathrm{C}$ to $-8.6^{\circ} \mathrm{C}$ at $0.25^{\circ} \mathrm{C} \cdot \mathrm{min}^{-1}$, held them for 1,8 , and $24 \mathrm{~h}$, rewarmed at

$107 \quad 0.25^{\circ} \mathrm{C} \cdot \mathrm{min}^{-1}$ and assessed survival (as above). In March 2017, we cooled three groups of four

108 mites from $0^{\circ} \mathrm{C}$ to $-9.0 \pm 0.7^{\circ} \mathrm{C}$ at $0.5^{\circ} \mathrm{C} \cdot \mathrm{min}^{-1}$, and held one group for each of $1 \mathrm{~h}, 12 \mathrm{~h}$, and one

109 week, before rewarming at $0.5^{\circ} \mathrm{C} \cdot \mathrm{min}^{-1}$.

110

111 To measure hemolymph osmolality, we amputated the front right leg under immersion

112 oil, extracted c. $20 \mathrm{~nL}$ of hemolymph, and determined osmolality and thermal hysteresis (Otago

113 Osmometers, Dunedin, New Zealand) as previously described (Crosthwaite et al. 2011). We

114 measured whole-body water content gravimetrically, as the difference between fresh mass and

115 mass after drying to a constant mass at $60^{\circ} \mathrm{C}$ (Sjursen and Sømme 2000). We rehydrated and

116 crushed these mites in $0.05 \%$ Tween 20 , and measured glycerol concentration

117 spectrophotometrically (details in Crosthwaite et al. 2011).

118

119 We compared SCP, osmolality, water content, and glycerol content using ANOVA in R

120 (version 3.2.2). We calculated LLT $_{50}$ from a generalized linear model in R and used non-

121 overlapping $95 \%$ confidence intervals to compare months. 


\section{Results}

123 All mites collected between November and March survived internal ice formation; a

124 smaller proportion survived freezing at other times (Table 1). SCP ranged from $-3.9^{\circ} \mathrm{C}$ (March 125 2016) to $-9.2^{\circ} \mathrm{C}$ (March 2017), and mean SCPs ranged from $-6.2 \pm 0.2^{\circ} \mathrm{C}$ in March 2016 to -8.4

$126 \pm 0.2^{\circ} \mathrm{C}$ in January 2017 (Fig. 1a). SCP differed significantly among sampling points (Fig. 1a),

127 but not in a manner that was associated with freeze tolerant mites having consistently higher or 128 lower SCPs than their freeze intolerant counterparts. LLT50 $( \pm 95 \%$ CI $)$ was lower in January ($\left.12920.0 \pm 2.7^{\circ} \mathrm{C}\right)$, than in March $(-7.4 \pm 3.2)$ or November $\left(-12.1 \pm 1.8^{\circ} \mathrm{C}\right.$; Fig. 1b). All mites in April 130 and March survived being frozen at $-8.6^{\circ} \mathrm{C}$ or $-9.0 \pm 0.7^{\circ} \mathrm{C}$ for $24 \mathrm{~h}$, and $8 / 12$ of March-collected 131 mites survived frozen for one week at $-9.0^{\circ} \mathrm{C}$.

132 Hemolymph osmolality ranged from 462 (March 2017) to 1997mOsm (February 2017;

133 Fig. 2a). Mean osmolality was highest in mites collected in January and February (Fig. 2a; Table

134 2). Water content was significantly lower in February 2017 than at other times of year, except

135 November 2016 (Figure 2a). We did not observe thermal hysteresis in any hemolymph sample

136 and saw no spicular ice crystal growth suggestive of ice-binding activity (Crosthwaite et al.

137 2011). Glycerol concentration was highest in midwinter (Fig. 2b). 
To our knowledge, this is the first report of freeze tolerance in a microarthropod. Not all

142 individuals survive internal ice formation in autumn, but by midwinter (January and February),

143 Allothrombium sp. can survive at least one week in a frozen state.

The supercooling point was lowest in midwinter, but there did not appear to be a strong association between SCP and cold tolerance, unlike in many freeze-tolerant insects, and the total

147 range of mean $\mathrm{SCP}$ is only c. $2^{\circ} \mathrm{C}$ in Allothrombium sp., compared to seasonal shifts of $10^{\circ} \mathrm{C}$ or 148 more in other freeze tolerant species (Duman 2001). The supercooling point was c. $1.5^{\circ} \mathrm{C}$ higher 149 in March 2016 than in March 2017 (Fig. 1A). We identify two possible explanations for this that 150 may not simply be due to inter-annual variation. First, the March 2016 sample was collected on 151 March 26th, much later in the month than the March 2017 sample (collected on March 6th); the 1522016 sample may perhaps be better reflective of SCP in the spring (we note it does not differ 153 from the April and May timepoints). Second, the March and April 2016 SCPs were measured by 154 cooling the mites at $0.25^{\circ} \mathrm{C} \cdot \mathrm{min}^{-1}$, whereas the 2017 mites were cooled at $0.5^{\circ} \mathrm{C} \cdot \mathrm{min}^{-1}$. Slower 155 cooling rates do lead to higher SCPs (Salt 1966), so this could explain the discrepancy, although

156 the likely presence of ice nucleating agents would be expected to at least partially mitigate this 157 effect. Either way, a difference in mean SCP of a few ${ }^{\circ} \mathrm{C}$ is unlikely to be biologically 158 significant, and reflects the overall small range of SCPs in adult Allothrombium sp., and suggests 159 selection for a consistently high supercooling point. Allothrombium sp. is a large mite (fresh mass $4.1 \pm 1.4 \mathrm{mg}$ in the animals in our study), 162 about twenty times the size of the c. $0.2 \mathrm{mg}$ Alaskozetes antarcticus (Block 1977). This relatively 
163 large size does not explain the high SCP nor imply an inability to depress the SCP in the winter;

164 non-cold-hardy insects of comparable size to Allothrombium sp., such as Drosophila, have SCPs

165 below $-15^{\circ} \mathrm{C}$ without special adaptations (Strachan et al. 2011), and much larger insects can

166 maintain very low SCPs (e.g. the 70-100 mg emerald ash borer Agrilus planipennis has a mean

167 SCP below $-30{ }^{\circ} \mathrm{C}$ in winter; Crosthwaite et al. 2011). SCP depression may not be possible for

168 soft-bodied species that (like Allothrombium sp.) are routinely exposed to ice nucleators from the

169 habitat. We speculate that this high probability of freezing (alongside year-round activity) could

170 have favored evolution of freeze tolerance in this species, as has been postulated for freeze

171 tolerance more generally (Toxopeus and Sinclair in press). Interestingly, these mites appear to

172 have adopted a divergent strategy to the cryoprotective dehydration used by Collembola in

173 similar habitats to avoid freezing (Sørensen and Holmstrup 2011).

174

175 Hemolymph osmolality was highest in midwinter. Decreased water content accounts for

176 c. $215 \mathrm{mOsm}$ of that increase, with another $15 \mathrm{mOsm}$ from increased [glycerol]. Glycerol has

177 been reported as a cryoprotectant in other arachnids (Aitchison and Hegdekar 1982; Kirchner

178 and Kestler 1969; Young and Block 1980) and is thought to enhance freeze tolerance by

179 stabilising macromolecules and reducing ice content and minimum cell volume (Lee 2010).

180 Although our small sample sizes (and consequently high variance) mean that we probably lack

181 statistical power to detect small differences in [glycerol], the magnitude of the change from

182 summer to winter $(\sim 15 \mathrm{mM})$ is substantially lower than the large changes observed in other

183 mites; for example, the freeze-avoidant $A$. antarcticus accumulates c. $0.5 \mathrm{M}$ glycerol (Young and

184 Block 1980). Approximately 530 mOsm remain unaccounted for; we hypothesize that other

185 osmotically-active agents (such as other polyols or amino acids, see Sinclair and Toxopeus, in 
186 press) contribute to the increase of hemolymph osmolality could also act as cryoprotectants.

187 Possibly, the small decrease in SCP in midwinter results from this increased osmolality.

In arachnids, freeze tolerance has evolved in two desert scorpions (Crawford and Riddle

190 1975; Whitmore et al. 1985), but not in any other mites as far as we are aware (Cannon and

191 Block 1988). Winter temperatures in southwestern Ontario can be highly variable (see, e.g.,

192 Marshall and Sinclair 2012), and we suggest that this thermal variability coupled with winter

193 activity (which likely precludes the accumulation of very high cryoprotectant concentrations),

194 and extensive environmental moisture (promoting inoculative freezing) has favored freeze

195 tolerance in this species. Thus, we show that neither small size nor a phylogenetic tendency

196 towards freeze avoidance in mites prevents them from evolving freeze tolerance, and we

197 speculate that other mites in similar circumstances may also be freeze tolerant. 


\section{Acknowledgements}

199 We acknowledge support from the Natural Science and Engineering Research Council of Canada

200 via an Alexander Graham Bell Canada Graduate Scholarship to SEA and a Discovery Grant to

201 BJS. Thanks also to Peter Duenk, Kurtis Turnbull, Brynne Duffy, and John Ciancio for

202 assistance with field collections; Jackie Lebenzon, Jantina Toxopeus, and Lamees Mohammad

203 for laboratory assistance; and Victoria Nowell (Canadian National Collection) and Cal Welbourn

204 (Florida Department of Agriculture and Consumer Services) for mite identification. This ms was

205 greatly improved by the constructive comments of three anonymous reviewers.

206

207 
209

210

211

212

213

214

215

216

217

218

219

220

221

222

223

224

225

226

227

228

229

230

231

232

233

234

235

236

237

238

239

240

241

242

243

244

245

246

247

248

249

250

251

252

Aitchison, C.W., and B.M. Hegdekar. 1982. Cryoprotectants in winter-active collembolans and spiders. Cryo-Lett 3: 310-311.

Block, W. 1977. Oxygen consumption of the terrestrial mite Alaskozetes antarcticus (Acari: Cryptostigmata). J Exp Biol 68: 69-87.

Cannon, R.J.C., and W. Block. 1988. Cold tolerance of microarthropods. Biol Rev 63: 23-77.

Crawford, C.S., and W.A. Riddle. 1975. Overwintering physiology of the scorpion Diplocentrus spitzeri. Physiol Zool 48: 84-92.

Crosthwaite, J.C., S. Sobek, D.B. Lyons, M.A. Bernards and B.J. Sinclair. 2011. The overwintering physiology of the emerald ash borer, Agrilus planipennis Fairmaire (Coleoptera: Buprestidae). J Insect Physiol 57: 166-173.

Duman, J.G. 2001. Antifreeze and ice nucleator proteins in terrestrial arthropods. Annu Rev Physiol 63: 327-357.

Kirchner, W., and P. Kestler. 1969. Untersuchungen zur Kälteresistenz der Schilfradspinne Araneus cornutus (Araneidae). J Insect Physiol 15: 41-53.

Lee, R.E. 1991. Principles of Insect Low Temperature Tolerance. pp. 17-46 in R.E. Lee and D.L. Denlinger, eds. Insects at Low Temperature. Chapman and Hall, New York.

Lee, R.E. 2010. A primer on insect cold tolerance. pp. 3-34 in D.L. Denlinger and R.E. Lee, eds. Low temperature biology of insects. Cambridge University Press, New York.

Marshall, K.E., and B.J. Sinclair. 2012. Threshold temperatures mediate the impact of reduced snow cover on overwintering freeze-tolerant caterpillars. Naturwissenschaften 99: 33-41.

Salt, R.W. 1966. Effect of cooling rate on the freezing temperature of supercooled insects. Can J Zool 44: 655-659.

Sinclair, B.J., A. Addo-Bediako and S.L. Chown. 2003. Climatic variability and the evolution of insect freeze tolerance. Biol Rev 78: 181-195.

Sinclair, B.J., L.E. Coello Alvarado and L.V. Ferguson. 2015. An invitation to measure insect cold tolerance: methods, approaches, and workflow. J Therm Biol 53: 180-197.

Sjursen, H., and L. Sømme. 2000. Seasonal changes in tolerance to cold and desiccation in Phauloppia sp. (Acari, Oribatida) from Finse, Norway. J Insect Physiol 46: 1387-1396.

Sørensen, J.G., and M. Holmstrup. 2011. Cryoprotective dehydration is widespread in Arctic springtails. J Insect Physiol 57: 1147-1153.

Strachan, L.A., H.E. Tarnowski-Garner, Marshall, K.E., and B.J. Sinclair. 2011. The evolution of cold tolerance in Drosophila larvae. Physiol Biochem Zool 84: 43-53.

Toxopeus, J., and B.J. Sinclair. in press. Mechanisms underlying insect freeze tolerance. Biol Rev. DOI: $10.1111 /$ brv. 12425.

Whitmore, D.H., R. Gonzalez and J.G. Baust. 1985. Scorpion cold hardiness. Physiol Zool 58: 526-537.

Young, S.R., and W. Block. 1980. Experimental studies on the cold tolerance of Alaskozetes antarcticus. J Insect Physiol 26: 189-200.

Zachariassen, K.E., and E. Kristiansen. 2000. Ice nucleation and antinucleation in nature. Cryobiology 41: 257-279.

Zhang, Z.-Q. 1998. Biology and ecology of trombidiid mites (Acari: Trombidioidea). Exp Appl Acarol 22: 139-155. 


\section{Tables}

254 Table 1: Freeze tolerance in Allothrombium sp. We cooled mites until c. 50\% froze, then 255 removed them from the cold for recovery.

\begin{tabular}{lcccc}
\hline & \multicolumn{2}{c}{ Frozen } & \multicolumn{2}{c}{ Unfrozen } \\
\cline { 2 - 5 } Date collected & No. alive & No. dead & No. alive & No. dead \\
\hline March 2016 & 9 & 0 & 8 & 1 \\
September 2016 & 5 & 3 & 8 & 0 \\
October 2016 & 2 & 2 & 4 & 0 \\
November 2016 & 8 & 0 & 8 & 0 \\
January 2017 & 7 & 0 & 3 & 0 \\
\hline
\end{tabular}

256

257 


\section{Figure Legends}

259 Figure 1: Cold tolerance of field-collected red velvet mites, Allothrombium sp. (a) Mean \pm SEM 260 supercooling point (SCP; numbers indicate sample size; different letters indicate points that are

261 significantly different, $\mathrm{F}_{7,147}=22.07, \mathrm{p}<0.01$ ). (b) Survival after 1 h cold exposure; curves are the 262 result of a generalized linear model with 95\% confidence intervals shown in grey. Note that 263 cooling rates in the $2015-2016$ winter were $0.25^{\circ} \mathrm{C} \cdot \mathrm{min}^{-1}$, but $0.5^{\circ} \mathrm{C} \cdot \mathrm{min}^{-1}$ in the $2016-17$ winter 264 for both datasets.

265

266 Figure 2: Hemolymph composition of overwintering red velvet mites, Allothrombium sp. (a)

267 Water content, osmolality; (b) glycerol concentration. Different letters indicate points that are 268 significantly different (Water content: $F_{4,48}=6.33, p<0.01 ;$ Osmolality: $F_{3,24}=21.88, p<0.001$;

269 [glycerol]: $\mathrm{F}_{4,21}=3.52, \mathrm{P}=0.03$ ), numbers indicate sample sizes; mean \pm SEM shown throughout. 